\title{
El rol del derecho en la construcción de identidades de género: replanteando el análisis de género desde los aportes de la teoría crítica
}

\author{
Susy Garbay Mancheno*
}

\section{RESUMEN}

Este trabajo recoge algunos de los debates propuestos por las teorías críticas, que ponen de relieve el análisis del derecho más allá de su aspecto formal, poniendo en evidencia que el derecho actúa en diferentes dimensiones produciendo categorías que a primera vista son de difícil identificación, pero que son relevantes en la producción de significados que aportan en el mantenimiento del orden social imperante. Desde esta perspectiva, el derecho es observado como un discurso social que produce el objeto sobre el que interviene, dota de sentido a las conductas de las personas y legitima las estructuras de dominación. Las teorías feministas que se adscriben a esta posición proponen complejizar la relación género y derecho, identificando en su discurso los códigos culturales que utiliza para la construcción de las identidades de género.

Palabras Clave: derecho, género, feminismo.

\section{ABSTRACT}

This paper gathers some of the debates proposed by critical theories, which emphasize on the analysis of law beyond its formal aspect, providing evidence that the law acts in different dimensions, thus producing categories that, at first sight, are identified with difficulty, but are nonetheless relevant in the production of meanings that contribute to keeping the prevailing social order. From this perspective, the law is observed as a social discourse that produces the object over which it intervenes, gives meaning to people's behavior and legitimizes the structures of domination. Feminist theories, which hold on to this position, propose the promlematization of the gender and law relationship, identifying in its discourse the cultural codes that are used in the construction of gender identities.

KEYWORDS: law, gender, feminism.

* Docente titular de derechos humanos de la Facultad de Jurisprudencia de la Universidad Central del Ecuador, y docente de los Programas de Derecho Constitucional y Derechos Humanos de la Universidad Andina Simón Bolívar, Sede Ecuador. 


\section{INTRODUCCIÓN}

in duda los estudios de género han enriquecido los debates académicos en las $\curvearrowright$ ciencias sociales. Particularmente en el derecho, la introducción de esta categoría ha conllevado rupturas en la lógica positivista que caracteriza su formulación y aplicación. No obstante, los debates de género en el derecho todavía aparecen marginales y su estudio es específico y no transversal, relacionando insistentemente la categoría género exclusivamente con las mujeres.

El trabajo que se presenta en estas líneas pretende ofrecer algunos elementos que permitan complejizar el análisis del derecho, para lo cual, sin la pretensión de hacer una síntesis exhaustiva, se hace una revisión de los aportes de las teorías jurídicas críticas feministas. De estas posiciones, se rescata en especial la que propone observar al derecho trascendiendo su aspecto formal, considerándolo más bien como un discurso social que se expresa en distintas dimensiones, cada una cargada de elementos simbólicos que generalmente son pasados por alto, pero que tienen un peso importante en la construcción cotidiana del orden patriarcal y en la reproducción de modelos de masculinidad y feminidad funcionales al sistema de dominación.

Los elementos que ofrece esta perspectiva resultan relevantes para problematizar la relación género-derecho, buscando en su formulación y aplicación esos aspectos simbólicos que un simple estudio obvia, asumiendo sin cuestionamiento que el sexismo en el derecho se supera con la inclusión de las mujeres en sus normas, o tipificando tipos penales para sancionar conductas que afectan especialmente a las mujeres, o porque quienes lo aplican son cada vez más mujeres, cuyo punto de vista sería suficiente para garantizar la inclusión del enfoque de género en el derecho.

Finalmente, con estos planteamientos, se hace una breve revisión del discurso jurídico ecuatoriano, a partir de algunas figuras legales creadas específicamente para controlar el cuerpo y la sexualidad de las mujeres, identificando los elementos simbólicos que contribuyen en el fortalecimiento de los imaginarios que sostienen el sistema patriarcal.

\section{EL DERECHO BAJO LAS MIRADAS FEMINISTAS CRÍTICAS}

En el campo del derecho, el uso del género como categoría de análisis desmitificó las características de objetividad, racionalidad y neutralidad que Kelsen le asignó a esta disciplina para justificar su carácter científico, proponiendo la necesidad de descontaminar el derecho de cualquier influencia ideológica, moral, política o socio- 
lógica. ${ }^{1}$ Diversas corrientes feministas han cuestionado estas características, identificándolo más bien como un instrumento del orden patriarcal, utilizado para normalizar las conductas de hombres y mujeres, estableciendo estándares de privilegio para los primeros, y de subordinación para las segundas.

Frances Olsen es una de las autoras feministas que sistematiza las críticas feministas al derecho. Su trabajo parte señalando que el pensamiento liberal clásico, desde su origen hasta la actualidad, se ha configurado a base de dualismos dicotómicos como, por ejemplo, racional e irracional; concreto y abstracto; objetivo y subjetivo. Cada uno de los componentes de los dualismos están sexualizados y jeraquizados, sobrevalorando las categorías que están relacionadas con lo masculino, como lo racional, objetivo, concreto, etc., mientras que la otra parte de los dualismos, asociada a los atributos femeninos, es desvalorizada. El derecho ha sido identificado con la parte de los dualismos masculinos, dada su caracterización como objetivo, racional y universal. ${ }^{2}$

Olsen identifica tres categorías de críticas feministas al derecho que responden, a su vez, a cada una las estrategias feministas que han surgido para combatir el sistema de binarios opuestos, sea cuestionando la sexualización, la jerarquización de los dualismos, o rechazando ambas determinaciones. En la primera categoría de críticas jurídicas, que la denomina reformista, ubica aquellas posiciones que señalan que el derecho no es racional, objetivo, ni universal, pues históricamente se ha evidenciado que la regulación legal referente a las mujeres ha estado encaminada a la negación del reconocimiento de sus derechos o a la restricción en el ejercicio de los mismos, aspectos que denotan claramente una ausencia de objetividad y racionalidad.

Desde esta categoría de críticas feministas, se han planteado las principales reformas legales tendientes al reconocimiento de derechos, en especial en lo relacionado a la igualdad formal y posteriormente a la igualdad material. Al mismo tiempo, se denunció que la noción de igualdad es relacional y se construye en función de los hombres, de manera que las normas sobre discriminación sexual operan en un modelo masculino. ${ }^{3}$

En esta categoría también se identifican aquellas críticas que denuncian que la esfera privada no ha sido objeto de regulación, evidenciando con ello un desprecio estatal por las necesidades de las mujeres, cuya cotidianidad se reproduce en ese espacio. Estas críticas alentaron, en la mayor parte de los Estados, el debate y la colocación en

1. Hans Kelsen, La teoría pura del Derecho (Buenos Aires: EUDEBA, 1941), 55-64.

2. Frances Olsen, "El sexo del derecho", en Christian Courtis, comp., Desde otra mirada. Textos de teoría crítica del Derecho (Buenos Aires: EUDEBA, 2001), 307.

3. Ibíd., 314. 
la agenda pública de la violencia doméstica, reclamando la intervención punitiva del Estado frente a este tipo de conductas violentas.

En opinión de Olsen, una segunda categoría de críticas jurídicas feministas reconoce en el derecho el paradigma del poder masculino, pero no cuestiona la caracterización del derecho como universal, objetivo y racional. Desde esta posición no se descarta la posibilidad de modificar la raíz patriarcal del derecho, no obstante reconoce las limitaciones que tienen las reformas legales y el litigio judicial en lograr cambios sociales, si no van de la mano de transformaciones estructurales en los ámbitos económicos, sociales y culturales. ${ }^{4}$

La tercera categoría de cuestionamientos al derecho, a la que Frances Olsen se adscribe, es la denominada teoría jurídica crítica feminista, 5 que toma elementos de las categorías anteriores. Desde esta posición no se dejan de reconocer las ventajas obtenidas en el reconocimiento y ejercicio de derechos de las mujeres mediante las reformas legales realizadas en las últimas décadas, pero se insiste en que el derecho no es abstracto, ni objetivo, ni racional, pues el "razonamiento jurídico y las batallas judiciales no son tajantemente distinguibles del razonamiento moral y político y de las batallas morales y políticas". ${ }^{6}$

Esta categoría de críticas jurídicas, si bien reconoce una pérdida de fe en el razonamiento jurídico y en la retórica de los derechos, no representan una postura pesimista frente al derecho, pero sí propone complejizar su análisis sin perder de vista los contextos de poder económico, político, sexual en los que se formula y se aplica.

Carol Smart complejiza el planteamiento de Olsen, advirtiendo que los argumentos que califican de sexista o masculino al derecho corren el riesgo de someterse a un determinismo biológico. ${ }^{7}$ Con ello no rechaza la idea de que el derecho sea sexista, pues reconoce que las instituciones legales ofrecen un tratamiento discriminatorio a las mujeres, como por ejemplo en las normas relacionadas al matrimonio y la prostitución. La preocupación de la autora es válida, ya que la calificación del derecho como

4. Ibíd., 317.

5. Estas críticas se nutren en las discusiones promovidas en el movimiento conformado por juristas académicos, denominado Critical Legal Studies, que surgió en Estados Unidos en los años sesenta y que pusieron en cuestionamiento el alcance de las técnicas jurídicas, desmontando el imaginario de que el Derecho ofrecía soluciones sociales y que para lograrlo era suficiente el uso del razonamiento jurídico. Ver en este sentido, Robert W. Gordon, "Nuevos desarrollos de la teoría jurídica", en Christian Courtis, comp., Desde otra mirada. Textos de teoría crítica del Derecho (Buenos Aires: EUDEBA, 2001); y Dunkan Kennedy, "La crítica de los derechos en los Critical Legal Studies". Disponible en 〈http://duncankennedy.net/documents/La\%20critica\%20de $\% 2010$ \% $\% 20$ derechos\%20en\%20cls.pdf〉.

6. Olsen, "El sexo del derecho", 319.

7. Carol Smart, "La teoría feminista y el discurso jurídico", en Haydée Birgin, comp., El Derecho en el género y el género en el Derecho (Buenos Aires: Biblos, 2000), 38. 
sexista impide observar los aspectos complejos y neurálgicos del derecho, creando erróneamente la idea de que el sexismo jurídico podría ser superado con la inclusión de normas que ofrezcan a las mujeres el mismo tratamiento que a los varones, o simplemente visibilizando a las mujeres en el lenguaje jurídico, respuestas que la autora califica como reduccionistas, pues no se observa la diferencia sexual como un problema estructural, "enquistada en el modo en el que comprendemos y negociamos el orden social". 8

Smart también rechaza la denominación del derecho como masculino, porque tampoco escapa de un determinismo biológico. Argumenta que la masculinidad del derecho se ha explicado a partir de las características de neutralidad y objetividad, que al mismo tiempo describen los atributos masculinos. Smart encuentra en este enfoque algunas contradicciones, pues considera incoherente apelar justamente a esos atributos para formular la noción de igualdad, lo que en su opinión sería equivalente a que las mujeres sean tratadas con los valores masculinos. ${ }^{9}$

Por otro lado, al describir el derecho como masculino, hace suponer que, al ser el varón el referente biológico del derecho, protege los derechos de todos los varones como categoría homogénea, lo cual no es preciso, así como tampoco es cierto que el derecho ofrece el mismo tratamiento a todas las mujeres. Por lo tanto los valores y las prácticas que describen lo masculino o lo varonil no deben obligatoriamente anclarse al varón como referente biológico. ${ }^{10}$ Esta reflexión es relevante pues suele justificarse que, si las decisiones judiciales fueran adoptadas por mujeres, el derecho no sería sexista, lo cual constituye una falacia pues las mujeres también son portadoras de los valores del patriarcado.

Smart no descalifica estos planteamientos pues reconoce que han servido para poner en evidencia la discriminación de las mujeres en el derecho, y por lo tanto han sido un aporte para su redefinición. No obstante, le preocupa que estos determinismos estanquen el análisis feminista, pretendiendo que la categoría de género opere como una especie de fórmula mágica que, al ser aplicada, modifique el derecho a favor de las mujeres, cuando este no se formula al margen de un contexto de dominación patriarcal. ${ }^{11}$

Ahora bien, el orden patriarcal tiene varias expresiones; así, en el ámbito latinoamericano, está marcado por el proceso de colonización. Algunos debates feministas latinoamericanos proponen incluir la categoría de interseccionalidad para identificar la exclusión de las mujeres "no blancas" de los discursos y las luchas que se han lle-

\footnotetext{
8. Ibíd., 36 .

9. Ibíd., 37.

10. Ibíd., 36 .

11. Ibíd., 40.
} 
vado a cabo en nombre de la "mujer". ${ }^{12}$ Esta propuesta merece ser considerada en el análisis discurso jurídico para identificar cómo opera en la construcción de las identidades femeninas y masculinas en relación con el origen racial y la condición social en el contexto ecuatoriano.

\section{EL DERECHO COMO DISCURSO SOCIAL}

La propuesta de Carol Smart se enmarca en las teorías críticas jurídicas desarrolladas en las últimas décadas, que han puesto en cuestionamiento la retórica de los derechos y la apelación insistente al razonamiento jurídico para protegerlos, pues es evidente que, al mismo tiempo que existen avances en el reconocimiento formal e inclusive en el desarrollo de su contenido, se continúa legitimando el sistema de dominación. Ante esta constatación se propone trascender del análisis de las formas evidentes en que el sistema legal perjudica a quienes carecen de poder, prestando atención a aquellos aspectos en que el derecho "parece a primera vista básicamente no controvertido, neutral y aceptable". ${ }^{13}$

Robert W. Gordon, uno de los exponentes de estas posturas, afirma que el derecho, tal como la religión, está configurado por un conjunto de creencias que operan con otras no jurídicas, para convencer a las personas que todas las relaciones de poder son "naturales y necesarias". ${ }^{14}$ Por lo tanto el análisis del derecho desde una mirada crítica obliga a identificar e interpretar la forma en que el discurso jurídico opera para interconectar esas creencias, que dan lugar a estructuras jurídicas, en forma de "códigos culturales complejos". ${ }^{15}$

Desde esta perspectiva, intentar comprender el derecho exclusivamente como norma es limitado y limitante, pues el derecho debe ser observado como un discurso social que se expresa en diferentes ámbitos, enunciando los conflictos que se producen en un momento histórico determinado. ${ }^{16}$ En opinión de Alicia Ruiz, el discurso jurídico puede identificarse en distintas dimensiones, como en la producción de normas, en la interpretación de las normas que se convierte en doctrina, en la jurisprudencia, y en un nivel más oculto del que forman parte las "creencias y mitos" que constituyen

12. María Lugones, “Colonialidad y Género", Tabula Rasa, Revista del Colegio Mayor de Cundinamarca, No. 9 (julio-diciembre 2008): 94.

13. Robert W. Gordon, "Nuevos desarrollos de la teoría jurídica", en Christian Courtis, comp., Desde otra mirada. Textos de teoría crítica del Derecho (Buenos Aires: EUDEBA, 2001), 307.

14. Ibíd, 333.

15. Ibíd., 334.

16. Alicia Ruiz, "Democracia y teorías críticas de fin de siglo", en Christian Courtis, comp., Desde otra mirada. Textos de teoría crítica del Derecho (Buenos Aires: EUDEBA, 2001), 11. 
determinantes ideológicos que se colocan en el imaginario social para legitimar el orden social. ${ }^{17}$

Estos planteamientos en gran medida están influenciados por la propuesta de Foucault, quien propuso en los años sesenta un examen complejo en la historia de las ideas, de los conceptos, del pensamiento, planteando que estos no pueden ser observados al margen de una serie de ideas conexas y hechos que son determinantes en su constitución. Los conceptos, las ideas y las ciencias no son individualidades históricas; son "categorías reflexivas, principios de clasificación, reglas normativas [...] son hechos de discursos que merecen ser analizados al lado de los otros, con los cuales tienen, indudablemente, relaciones complejas, pero que son caracteres intrínsecos, autóctonos y universalmente reconocibles". ${ }^{18}$ Foucault propuso como operación interpretativa captar los enunciados del discurso, establecer su relación con otros enunciados y captar aquello que se oculta. ${ }^{19}$

El derecho está construido por una serie de enunciados a través de los cuales se establecen mandatos y se regulan las conductas de las personas. No hay un espacio de la vida que escape de la intervención del derecho. Ahora bien, en el discurso jurídico que aparece como neutro, en unos casos, y favorecedor con las mujeres, en otros, subyacen imaginarios y elementos simbólicos que mantienen intacto el orden de dominación patriarcal. Los elementos simbólicos de los enunciados del discurso jurídico, dice Pierre Bourdieu, son útiles e indispensables para instituir lo que ya está instituido:

El derecho es, sin duda, la forma por excelencia del poder simbólico de nominación que crea las cosas nombradas y, en particular, los grupos sociales, la forma en que confiere a estas realidades surgidas de sus operaciones de clasificación toda permanencia que una institución histórica es capaz de conferir a instituciones históricas, igual a la que tienen los objetos. ${ }^{20}$

El discurso jurídico opera simbólicamente, otorgando legitimidad a las estructuras sociales de dominación masculina, en opinión de Bourdieu, la representación androcéntrica de la reproducción social esta revestida por la objetividad de un sentido común. El discurso jurídico aparece como producto de un consenso práctico y dóxico de la división del mundo. ${ }^{21}$

17. Ibíd., 13 .

18. Michel Foucault, La arqueología del saber (Buenos Aires: Siglo XXI, 2013), 35.

19. Ibíd., 40-42.

20. Pierre Bourdieu, "Elementos para una sociología del campo jurídico", en Pierre Bourdieu y Ghunther Teubner, La fuerza del Derecho (Bogotá: Unidandes, 2000), 198.

21. Ibíd., 49. 


\section{EL DISCURSO JURÍDICO COMO PRODUCTOR DE IDENTIDADES DE GÉNERO}

La diferencia entre hombres y mujeres se ha construido a partir de algunas instituciones políticas sexuales como la virginidad, monogamia, maternidad obligatoria, heterosexualidad, prostitución, entre otras, dando lugar a concepciones que han justificado el control del cuerpo y la sexualidad de las mujeres a través del derecho.

Como propone Foucault, los enunciados del discurso se relacionan complejamente unos con otros; ${ }^{22}$ así, el discurso jurídico es portador de las representaciones de las mujeres, que se han ido configurando a lo largo de la historia en un contexto simbólico e ideológico, dando lugar a un régimen de saber-poder, que ha sustentado un discurso sobre la identidad femenina construida a partir de las representaciones sexuales que han sido trasladadas al derecho.

La inferioridad de las mujeres y la superioridad de los varones han sido objeto de complejas explicaciones teóricas a lo largo de la historia. Claude Thomaset, estudiosa del pensamiento de Aristóteles, destaca que este pensador planteó que las mujeres eran una especie de macho incompleto, ya que debido a la baja temperatura corporal no podían producir un fluido con la capacidad creadora, como sí sucedía en el caso de los varones, cuya temperatura les permitía alcanzar ese grado de perfección. ${ }^{23}$

La doctrina aristotélica sobre la temperatura corporal de las mujeres se proyectó a la Edad Media y sirvió a la filosofía patrística para explicar la excepcional concepción de Jesús en el cuerpo de María. Tomás de Aquino afirma que la formación del embrión dotado de divinidad en el cuerpo de María tuvo su origen en el fluido menstrual que posteriormente se transformó en leche para alimentar al niño que nació de su vientre. ${ }^{24}$ De otro lado, la inferioridad de la mujer también sirvió para explicar la entrada del pecado al mundo. Según Tomás de Aquino, el demonio al proponerse separar al hombre del camino recto de la justicia lo atacó en su parte más débil, "tentando a la mujer, en la que era menor el don o la luz de la sabiduría". ${ }^{25}$ Asegura, además, que la perfección y la elevación no eran el destino de la mujer, y que esta cometió los pecados de la soberbia, curiosidad y desobediencia porque aspiró a la ciencia transgrediendo los límites que le estaban naturalmente marcados. ${ }^{26}$ Estas reflexiones dieron lugar al dog-

22. Foucault, La arqueología del saber, 35.

23. Claude Thomasset, "La naturaleza de la mujer", en Georges Duby y Michelle Perrot, dir., Historia de las mujeres (Madrid: Taurus, 2003), 86-7.

24. Tomás de Aquino, Compendio de Teología (Barcelona: Orbis, 1985), 162-86.

25. Ibíd., 150 .

26. Ibíd., 151. 
ma cristiano de la virginidad y santidad de María, y el del pecado representado por la mujer caída, Eva, modelos femeninos que se convertirán en arquetipos de la construcción de la identidad sexual femenina, en el discurso del derecho clásico y moderno.

El derecho romano, del cual el derecho ecuatoriano es receptor, consolidó la subordinación de las mujeres en los ámbitos privados y públicos, a través de instituciones jurídicas que han permanecido intactas durante siglos. Mediante la figura de la infamia, las mujeres estaban prohibidas de contraer matrimonio antes de un año luego de enviudar. ${ }^{27}$ Esta representación jurídica sobrevivió en la legislación ecuatoriana hasta hace poco tiempo, prohibiendo expresamente a la mujer viuda o divorciada contraer matrimonio dentro de los trescientos sesenta y cinco días contados desde la fecha de muerte del marido o de la inscripción de la sentencia de divorcio en el Registro Civil. ${ }^{28}$ De igual forma, el Código Civil ecuatoriano conservó hasta su reciente reforma la disposición por la cual, ante la falta de determinación expresa, se establecía que el marido era el administrador de la sociedad conyugal. Estas normas tienen un alto contenido simbólico respecto a la inferioridad de las mujeres.

El Derecho penal, por su parte, representa por excelencia el mecanismo de ejercicio de violencia legítima que tiene el Estado para controlar y disciplinar a las personas. En el caso de las mujeres, señala Alessandro Baratta, el sistema penal constituye un sistema subsidiario en la medida en que el control de las mujeres en las esferas de la reproducción, intercambio sexual, procreación y de la familia (orden privado) operan más bien mecanismos de control informal que se ejercen mediante el dominio patriarcal. ${ }^{29}$ Es decir, el orden patriarcal le ofrece la potestad para disciplinar a las mujeres a instituciones privadas y públicas, como la familia, la escuela, la medicina, etc., que cuentan con herramientas de control para moldear a las mujeres, que incluye la violencia física. El control de la sexualidad de las mujeres es uno de los fines centrales del patriarcado privado y del sistema punitivo formal que se activa cuando no pueden ser controladas por el primero.

En el derecho romano, el vínculo conyugal ofrecía al pater familias la autorización para disciplinar a las mujeres, pues junto con los siervos y los niños eran clasificadas como alienis iuris, personas sin independencia y sometidas a la manus o potestas. El vínculo conyugal facultaba al marido a asumir el poder disciplinario sobre la mujer y solamente ella estaba sujeta a las sanciones de adulterio por faltar a la fidelidad con-

27. Pedro Bonafonte, Instituciones de Derecho romano (Madrid: Reus, 1965), 186-7.

28. Estas disposiciones constaban en el Código Civil, publicado en el Suplemento del Registro Oficial No. 104, de 20 de noviembre de 1970, y derogadas mediante reforma publicada en el Registro Oficial No. 526 de 19 de junio de 2015.

29. Alessandro Baratta, "El paradigma de género. De la cuestión criminal a la cuestión humana", en Haydée Birgin, comp., La trampas del poder punitivo. El género del derecho penal (Buenos Aires: Biblos, 2000), 60. 
yugal. ${ }^{30}$ Siguiendo la tradición romana, la figura del adulterio en el Ecuador se incluyó en la ley penal de 1837, estableciendo, además de la pena privativa de la libertad, la pérdida de sus gananciales; también contemplaba el indulto conyugal, es decir, la posibilidad de dejar sin efecto la sanción si el marido la perdonaba y consentía en "volver a tomar a su mujer". ${ }^{31}$

La figura del perdón conyugal se mantuvo en el Código Penal hasta 1938, en la cual la representación de la mujer es la de objeto; por lo tanto, puede ser abandonada, castigada y redimida solo por el marido. La autorización del varón para castigar a la mujer adúltera estuvo implícita en el eximente penal vigente hasta 1983, por el cual se libraba de responsabilidad penal al cónyuge que golpee, hiera o mate al otro si lo sorprende en flagrante delito de adulterio. ${ }^{32} \mathrm{Si}$ bien la norma hace referencia al "cónyuge" como categoría neutra, no puede interpretarse el sentido de esta norma al margen del contexto ideológico, en el que históricamente se han construido los imaginarios de la sexualidad femenina y de la figura del adulterio.

La potestad del ejercicio punitivo en el ámbito privado no se ha otorgado exclusivamente al cónyuge, pues fue extensivo a los demás varones del hogar. Así, hasta el año 1989 estaba vigente en el Código Penal ecuatoriano la disposición por la cual se eximía de sanción penal al padre, abuelo o hermano que hiera, golpee o mate a la mujer, hija, nieta o hermana sorprendida en un acto carnal ilegítimo. ${ }^{33}$ Si bien la noción de acto carnal ilegítimo es ambigua, en general alude a las relaciones sexuales no autorizadas a las mujeres, es decir, las relaciones extra y prematrimoniales. El control de la sexualidad femenina ha sido uno de los fines centrales del patriarcado privado y del sistema punitivo formal que ratifica el poder de los varones para controlar el cuerpo de las mujeres, convirtiéndolas en objetos de apropiación en el ámbito real y también en el simbólico.

En estas figuras subyacen además las nociones del honor femenino, diferenciándolo del honor masculino. En el primer caso, la honestidad de las mujeres está construida simbólicamente a partir de la virginidad, elemento clave del arquetipo mariano de mujer. El honor masculino, que no se refiere a la ausencia de experiencia sexual,

30. Bonafonte, Instituciones de Derecho romano, 54-5.

31. “Art. 486. La mujer casada que cometiere adulterio, perderá los gananciales y todos los demás derechos de la sociedad conyugal, y será condenada a prisión por dos a seis años. Único. El marido puede suspender los efectos de estas penas perdonando a la mujer, y consintiendo reunirse a ella". Código Penal, Decreto Legislativo 0, Registro Auténtico 1837, de 14 de abril de1837.

32. Derogada una vez que el adulterio dejó de ser delito por lo dispuesto en artículo final del Código de Procedimiento Penal, Ley No. 143, publicada en Registro Oficial 511 de 10 de junio de 1983.

33. Derogado por Resolución del Tribunal de Garantías Constitucionales, publicado en Registro Oficial 224 de 3 de julio de 1989. 
representa el honor familiar, comprende aspectos como la valentía, la prudencia, nobleza, poder y la valoración del ser varón. ${ }^{34}$ Las mujeres se convierten en objetos simbólicos, portadoras de la condición social de los hombres, pues el orden de dominación masculina exige a las mujeres encarnar los atributos femeninos históricamente asignados. ${ }^{35}$

El sentido de propiedad respecto a las mujeres por parte de los varones es un dato relevante en la construcción de la subjetividad masculina, es parte del ethos masculino. Pierre Bordieu explica que la configuración de esta subjetividad opera mediante la dominación simbólica que se expresa en el habitus, que constituye un sistema de categorías, pensamientos y acciones que se expresa en esquemas mentales y corporales. ${ }^{36}$ Esta construcción simbólica, afirma, no se limita a una operación performativa que organiza la representación del cuerpo, sino que se convierte un sentido común por lo tanto incuestionable. ${ }^{37}$

Este aspecto se evidencia, por ejemplo, en la figura de femicidio, introducida en la legislación penal ecuatoriana hace pocos años. Algunos estudios sobre esta temática ponen en evidencia que entre las principales motivaciones de los asesinatos de las mujeres está el hecho de que las víctimas decidieron separarse de sus parejas, iniciar otra relación o por "celos". ${ }^{38}$ De este modo, a pesar de que el eximente penal por el cual se dejaba sin sanción penal al asesinato de la mujer que era encontrada en "acto carnal ilegítimo" fue derogado, el sentido común de la apropiación del cuerpo de las mujeres a través de la violencia extrema se mantiene intacto.

El honor se registra en el cuerpo, en la manera de pensar y actuar, es un ethos que "gobierna al hombre honorable" convirtiéndose en una fuerza superior que le hace asumir, como ineludibles, conductas o hechos que podrían parecer impensables. Según Bourdieu, el honor es el producto de una operación social de "nominación y de inculcación", que instituye una identidad social, convirtiéndose en un hábito, en una ley social asimilada. ${ }^{39}$

La virilidad en el habitus masculino tiene una connotación ética que se basa en las nociones del "virtus" y el "pundonor", así como en el principio de la conservación y el incremento del honor en la esfera pública, elementos que están relacionados a la vi-

34. Natalia León Galarza, La primera alianza. El matrimonio criollo, honor y violencia conyugal, Cuenca 1750-1800 (Quito: Nueva Editorial, 1997).

35. Pierre Bourdieu, La dominación masculina (Barcelona: Anagrama, 2000), 38.

36. Ibíd., 24.

37. Ibíd., 37.

38. Susy Garbay, "Femi(ni)cidio como expresión de dominio patriarcal", en Gina Benavides y Gardenia Chávez, edit., Horizonte de los derechos humanos. Ecuador 2012 (Quito: UASB, 2013), 250.

39. Ibíd., 67. 
rilidad física que se expresa en la fuerza o dominio sexual; ${ }^{40}$ también está relacionada a la habilidad para el combate y la aptitud para ejercer violencia. ${ }^{41}$

La honestidad femenina, por su parte, se diferencia de la honestidad masculina, pues es objeto de regulación y salvaguarda a través de diferentes dispositivos jurídicos. Así, por ejemplo, la sobrevaloración del honor se reflejó en los atenuantes penales en los casos de aborto e infanticidio cuando estas conductas tenían como propósito ocultar la deshonra de la madre; más aún, en el caso del infanticidio, el atenuante beneficiaba a los abuelos maternos que cometían el delito con el mismo propósito. ${ }^{42}$

Manifestando la alianza entre el discurso penal y la moral cristiana, la ley penal ecuatoriana también preveía de forma simbólica el resarcimiento del honor femenino mediante el matrimonio, tal como lo preveía la figura del rapto "con fines deshonestos" de una mujer menor de edad. Esta disposición establecía que no podía ser perseguido penalmente el raptor que se case con la menor, así como tampoco quienes participaron en el rapto, mientras no se declare definitivamente la nulidad del matrimonio. ${ }^{43}$ En esta norma subyacen elementos del discurso penal no explícitos, pero que mantienen simbólicamente la división moral de los roles femeninos y masculinos.

El énfasis en los fines deshonestos conlleva la idea de que el fin del rapto de una mujer menor de edad es mantener relaciones sexuales con ella, conducta considerada como "un grave atentado a la moral y al derecho", ${ }^{44}$ ya que no solo deshonra a la mujer sino también a su familia; en consecuencia, implícitamente se proponía como solución someter a la mujer que ha sido raptada a la institución matrimonial, que no solo constituye un contrato, pues bajo los preceptos cristianos es la unión sagrada de un hombre y una mujer, con la cual se redime el honor de la mujer y de la familia mancillados.

De igual forma, la alusión al honor femenino se hacía en la figura del estupro, que tipificaba las relaciones sexuales con una mujer honesta, sin recurrir a la fuerza sino a

40. Ibíd., 24.

41. Ibíd., 70.

42. El Código Penal vigente hasta el 2014 establecía en el art. 444 que tipificaba el aborto una sanción de uno a cinco años de prisión para la mujer que consentía en el aborto, pero al mismo tiempo atenuaba la pena de seis meses a dos años si el aborto tenía como fin ocultar la deshonra. De otro lado, en el art. 454, sancionaba con pena de dieciséis a veinticinco años de reclusión el asesinato de un hijo; sin embargo, el 453 establecía una pena atenuada de tres a seis años si se trataba de la muerte de un recién nacido provocada por la madre, o los abuelos maternos, con el fin ocultar la deshonra de la madre.

43. Esta figura estaba contemplada en el art. 532 vigente hasta el 2014 en que se promulgó el Código Orgánico Integral Penal.

44. Gaceta judicial, año LXXI, serie XI, No. 3, p. 350 (Quito, 29 de septiembre de 1967) Lexis. 
la seducción o engaño. ${ }^{45}$ De esta forma, el discurso jurídico penal fortalece el imaginario social de la mujer virtuosa que corresponde al arquetipo mariano, como aquella que merece "protección" estatal mediante la intervención punitiva.

De otro lado, está la representación de Eva, personificada en la prostituta, que ya no tiene honor que ser defendido, y, si bien la prostitución no es un delito, es una actividad que se ha desenvuelto entre la reglamentación y la ilicitud. Las figuras penales de la rufianería y el proxenetismo han sancionado la explotación de la prostitución y la promoción de su ejercicio fuera de los lugares permitidos por la ley. ${ }^{46}$ Los discursos que se han generado alrededor de la prostitución que van desde la condena, la justificación, hasta su reivindicación, suelen pasar por alto el contexto en el que surge y se configura:

La disociación histórica de la mujer es definida a partir de las necesidades del patriarca en cuanto hombre mítico, prototipo del género masculino. Así, la mujer "decente", madre y esposa, asexual, sometida al hombre, subsiste en la medida que se crean otras categorías de mujeres (la hetaira y ágata griegas), mujeres del placer, "sexuales" al servicio del patriarca. [...]. Con las primeras se establece el compromiso de "respaldarlas" y nombrar a sus hijos; con las segundas, no se adquiere compromiso alguno. ${ }^{47}$

El derecho patriarcal no protege a este arquetipo de mujer, pues no tiene honra que preservar, el acceso a su cuerpo está garantizado por códigos de conducta de mercado. Vale la pena recordar que el desprecio y la desvalorización a las prostitutas estaban expresamente establecidos en la ley ecuatoriana, al calificar a las "meretrices" como testigos no "idóneos" por falta de probidad, ${ }^{48}$ es decir, por falta de honradez ${ }^{49}$ De este modo, como afirma Carol Smart, el discurso jurídico como estrategia creadora de género, al mismo tiempo que configura la idea de la mujer en forma contraria a la de varón, discursivamente da lugar a la representación de diferentes tipos de mujeres: la puta, la víctima, la adúltera, etc..$^{50}$

Los elementos simbólicos de estas representaciones en el discurso jurídico penal no son insustanciales; tal como plantea Bourdieu, el discurso del derecho es capaz

45. Esta figura estuvo vigente hasta el 23 de junio de 2005, en que se realizó una reforma al Código Penal de entonces.

46. Esta figura se mantuvo en el Código Penal hasta 1998, reemplazándola por la de proxenetismo y conlleva las conductas de explotación y aprovechamiento de la prostitución.

47. José Salas y Álvaro Campos Guadamuz, Explotación sexual comercial y masculinidad (San José: OIT, 2004), 63.

48. Hasta el año 2004 en que se declaró inconstitucional el número 7 del art. 217 del Código de Procedimiento Civil se establecía que "las meretrices" no podían ser testigos por falta de probidad.

49. El diccionario de la Real Academia de la Lengua define probidad como honradez y rectitud.

50. Smart, "La teoría feminista y el discurso jurídico", 43. 
de producir efectos y hacer el mundo social. ${ }^{51}$ Si bien la honestidad femenina ha sido eliminada del lenguaje de las normas de la ley penal, el discurso jurídico penal no lo ha abandonado; de ese modo las mujeres siguen siendo evaluadas bajo esta categoría para definirla como víctima, aspecto que no responde a un patrón aislado sino a una constante. Este hecho tiene una implicancia directa en la eficacia de las normas que suponen una conquista en los derechos de las mujeres, relativizando su efectividad y acarreando la impunidad de conductas que las afectan. ${ }^{52}$

Las reflexiones planteadas evidencian la necesidad de dejar de observar el derecho simplemente como un conjunto de dispositivos y reglas que puedan ser modificados adoptando una forma más favorable hacia un grupo o grupos de personas.$^{53} \mathrm{El}$ derecho implica un proceso complejo de reproducción simbólica que no siempre es fácil de advertir.

\section{CONCLUSIONES}

1. Las reflexiones feministas han realizado un aporte a la epistemología de las ciencias sociales y del derecho. La conceptuación del género como categoría de análisis problematizó la supuesta naturaleza de las identidades masculinas y femeninas, evidenciando que el rol de subordinación de las mujeres en la sociedad no obedece a su naturaleza, sino a un constructo social que se ha ido configurando a lo largo de la historia. La introducción de los debates de género en el derecho demostraron que en su formulación y aplicación subyace una ideología de dominación y que, por lo tanto, las características de objetividad, racionalidad y universalidad, que el positivismo le asignó al derecho, constituían una ficción.

En las últimas décadas, las teorías jurídicas críticas feministas proponen complejizar la relación género-derecho, lo cual implica algunos desafíos; uno de ellos es observar el derecho como un discurso social creador de identidades de género funcionales al orden de dominación patriarcal. El reto es, entonces, comprender cómo opera el derecho en sus distintas dimensiones, para lo cual

51. Bourdieu, "Elementos para una sociología del campo jurídico", 198.

52. En el Plan Nacional de Erradicación de la Violencia de Género hacia la Niñez, Adolescencia y Mujeres, de 2008, se reconoce que uno de los factores que genera los elevados niveles de impunidad en los delitos de violencia sexual se debe, entre otros, a la reproducción de patrones socioculturales, que vuelve a la administración de justicia "altamente revictimizante, discriminante e ineficaz". Ver Plan Nacional de Erradicación de la Violencia de Género hacia la Niñez, Adolescencia y Mujeres, Decreto Ejecutivo reformatorio 1109 de 27 de mayo de 2008.

53. Smart, "La teoría feminista y el discurso jurídico", 48. 
es necesario observar aquellos elementos simbólicos que son determinantes en la reproducción de la ideología patriarcal.

2. En el ámbito ecuatoriano, en figuras del derecho civil y particularmente del derecho penal, se observan esos elementos simbólicos que configuran las identidades femeninas basadas en los arquetipos tradicionales, configurados a lo largo de la historia. Si bien la legislación ecuatoriana ha merecido una serie de reformas, que ha eliminado figuras arcaicas, conserva los estereotipos tradicionales sobre las mujeres y sus roles. Es decir, las reformas impulsadas en diferentes áreas del derecho no conllevan necesariamente una modificación de la ideología patriarcal. Esto es un aspecto importante que obliga a analizar el discurso jurídico ecuatoriano, en sus fases de formulación y aplicación, para identificar los mecanismos con los que cuenta y la forma en que opera, en la reproducción de las identidades femeninas considerando además otras categorías como raza y condición social.

\section{BIBLIOGRAFÍA}

Baratta, Alessandro. "El paradigma de género. De la cuestión criminal a la cuestión humana". En Haydée Birgin, comp., La trampas del poder punitivo. El género del derecho penal. Buenos Aires: Biblos, 2000.

Bonafonte, Pedro. Instituciones de Derecho romano. Madrid: Reus, 1965.

Bourdieu, Pierre. "Elementos para una sociología del campo jurídico". En Pierre Bourdieu y Gunther Teubner. La fuerza del Derecho. Bogotá: Uniandes, 2000.

---. La dominación masculina. Barcelona: Anagrama, 2000.

De Aquino, Tomas. Compendio de Teología. Barcelona: Orbis, 1985.

Foucault, Michel. La historia de la sexualidad, t. I. México: Siglo XXI, 2011.

---. Vigilar y castigar. México: Siglo XXI, 2009.

Gordon, Robert W. "Nuevos desarrollos de la teoría jurídica". En Christian Courtis, comp., Desde otra mirada. Textos de teoría crítica del derecho. Buenos Aires: EUDEBA, 2001.

Kelsen, Hans. La teoría pura del derecho. Buenos Aires: EUDEBA, 1941.

Kenney, Dunkan. "La crítica de los derechos en los Critical Legal Studies". Disponible en 〈www.palermo.edu/derecho/publicaciones/pdfs/.../071Juridica02.pdf〉.

León Galarza, Natalia. La primera alianza. El matrimonio criollo, honor y violencia conyugal, Cuenca 1750-1800. Quito: Nueva Editorial, 1997.

Moscoso, Martha. Y el amor no era todo...: Mujeres, imágenes y conflictos. Quito: Abya-Yala, 1996.

Olsen, Frances. "El sexo del derecho". En Christian Courtis, comp., Desde otra mirada. Textos de teoría crítica del derecho. Buenos Aires: EUDEBA, 2001. 
Ruiz, Alicia. "Democracia y teorías críticas de fin de siglo". En Christian Courtis, comp., Desde otra mirada. Textos de teoría crítica del Derecho. Buenos Aires: EUDEBA, 2001.

Salas, José Manuel, y Álvaro Campos Guadamuz. Explotación sexual comercial y masculinidad. San José: OIT, 2004.

Smart, Carol. "La teoría feminista y el discurso jurídico". En Haydée Birgin, comp., El Derecho en el género y el género en el Derecho. Buenos Aires: Biblos, 2000.

Thomasset, Claude. "La naturaleza de la mujer". En Georges Duby y Michelle Perrot, dir., Historia de las mujeres. Madrid: Taurus, 2003.

Zaffaroni, Eugenio. "El discurso feminista y el poder punitivo”. En Haydée Birgn, comp., Las trampas del poder punitivo. El género del derecho penal. Buenos Aires: Biblos, 2000.

\section{Otros}

Código Penal 1837, publicado en Registro Auténtico, 1837, de 14 de abril de 1837.

Código Penal 1889, publicado en Registro Auténtico, 1889, de 4 de enero de 1889.

Código Penal 1906, publicado en Suplemento de Registro Oficial No. 61, de 18 de abril de 1906.

Código Penal 1938, publicado en Registro Auténtico, de 22 de marzo de 1938.

Código Penal 1971, publicado en Suplemento de Registro Oficial No. 147, de 22 de enero de 1971.

Código Integral Penal 2014, publicado en Suplemento de Registro Oficial No. 180, de 28 de enero de 2014.

Gaceta judicial. Año LXXI. Serie XI. No. 3, p. 350 (Quito, 29 de septiembre de 1967) Lexis 〈http://www.silec.com.ec/webtools/esilecpro/Search/Jurisprudencia/JurisprudenciaSimple. aspx . 